Provided for non-commercial research and education use. Not for reproduction, distribution or commercial use.

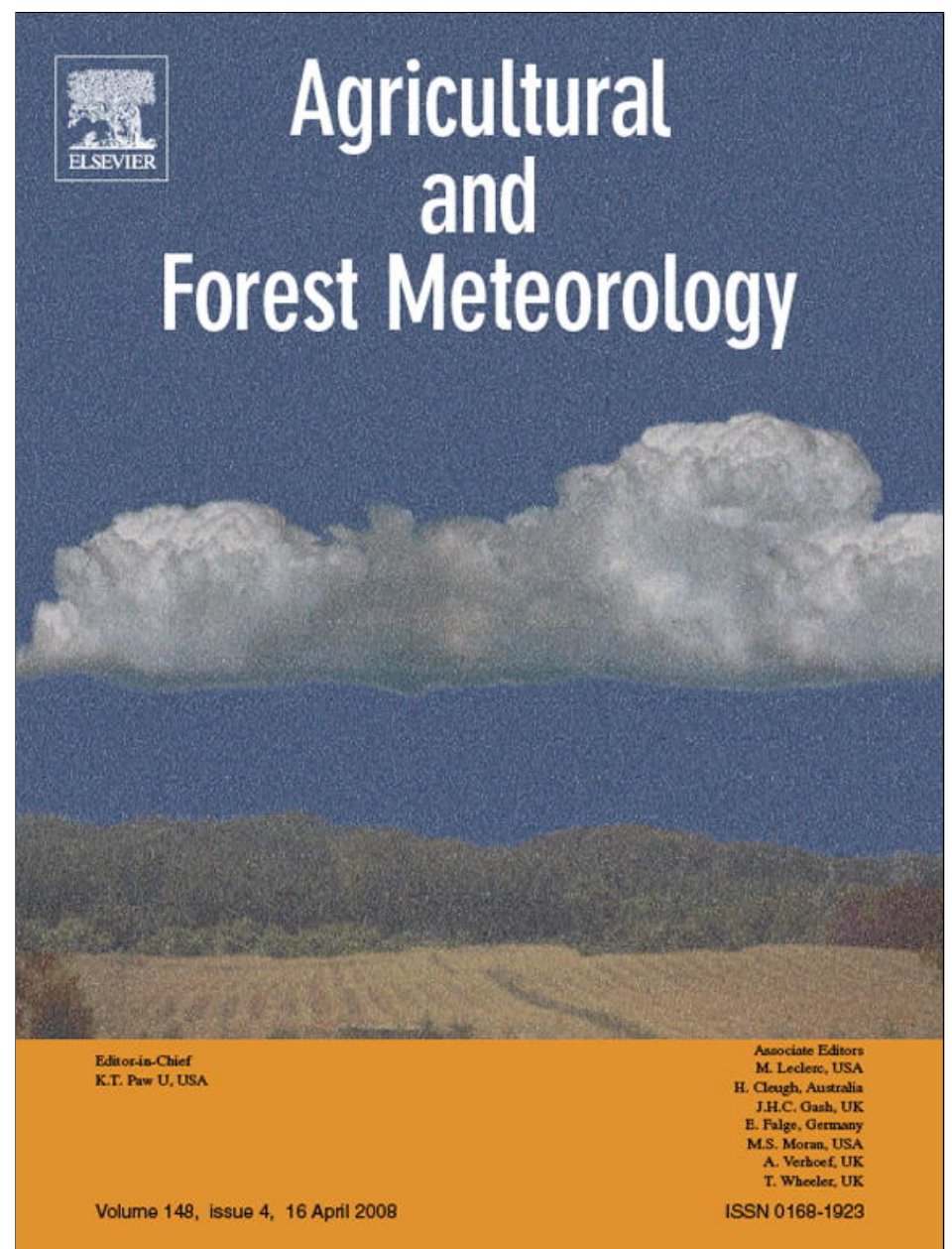

This article appeared in a journal published by Elsevier. The attached copy is furnished to the author for internal non-commercial research and education use, including for instruction at the authors institution and sharing with colleagues.

Other uses, including reproduction and distribution, or selling or licensing copies, or posting to personal, institutional or third party websites are prohibited.

In most cases authors are permitted to post their version of the article (e.g. in Word or Tex form) to their personal website or institutional repository. Authors requiring further information regarding Elsevier's archiving and manuscript policies are encouraged to visit:

http://www.elsevier.com/copyright 


\title{
Estimation of leaf area and clumping indexes of crops with hemispherical photographs
}

\author{
Valérie Demarez ${ }^{a, *}$, Sylvie Duthoit ${ }^{a, c}$, Frédéric Baret ${ }^{b}$, Marie Weiss $^{b}$, Gérard Dedieu $^{a}$ \\ ${ }^{a}$ CESBIO, 18 avenue Edouard Belin, 31401 Toulouse, France \\ ${ }^{\mathrm{b}}$ INRA CSE, Domaine Saint-Paul, Site Agroparc, 84914 Avignon Cedex 9, France \\ c University of Johannesburg, Department of Botany, PO Box 524, Auckland Park 2006, Johannesburg, South Africa
}

\section{A R T I C L E I N F O}

\section{Article history:}

Received 21 May 2007

Received in revised form

14 November 2007

Accepted 19 November 2007

\section{Keywords:}

Effective leaf area index

Hemispherical photography

Clumping index

Crops

CAN_EYE software

\begin{abstract}
A B S T R A C T
Among many indirect approaches to retrieve effective leaf area index (LAI), hemispherical photography is now widely used by the scientific community in forestry applications. A recent software (CAN_EYE) is used to estimate effective and true LAI from unidirectional gap fractions measured in crops. The effective LAI is computed with the Poisson law whereas the true LAI is estimated introducing a clumping index in the Poisson law. The clumping index estimation is based on the Lang and Xiang averaging method. CAN_EYE includes an automatic image classification and allows the processing of series of photographs which is mandatory to sample the spatial variability of the canopy. The objective of this study is to determine if the use of the clumping index in the gap fraction formulation improves seasonal LAI estimates of crops. Hemispherical photographs were taken throughout two growing seasons over wheat, sunflower and maize canopies. CAN_EYE LAI estimates were then compared to destructive LAI. The conditions under which photographs were acquired and processed are discussed. For the three crops studied here, the minimum distance required between camera and canopy is $1 \mathrm{~m}$. When feasible, there is a clear advantage in acquiring the images from above canopies and on overcast days to facilitate the image classification. For wheat and sunflower, the best LAI estimates are assessed with effective LAI (RMSE of 0.15, $y=0.9540 x$ for wheat and RMSE of $0.38, y=0.8427 x$ for sunflower). For maize, the best LAI estimates are obtained using the clumping index (RMSE of 0.39 and $y=0.9010 x$ ). Despite good fits between CAN_EYE and destructive LAI estimates, compensation effects between leaf area index and leaf angle distribution may occur during the inversion procedure. Moreover, values of clumping index given by CAN_EYE are in certain cases correlated with the size of the cells used to divide photographs. The Lang and Xiang averaging method introduced into CAN-EYE should be improved.
\end{abstract}

(C) 2007 Elsevier B.V. All rights reserved.

\section{Introduction}

Leaf area index (LAI) is a key variable used in many biogeophysical and chemical exchange models focusing on carbon and water fluxes (Sellers et al., 1997; Calvet et al.,
1998; Wang and Leuning, 1998) and therefore required by a broad scientific community (Morisette et al., 2006). Numerous approaches of destructive and non-destructive LAI measurements have been developed (see reviews methods in Ross, 1981; Gower et al., 1999; Kussner and Mosandl, 2000;

\footnotetext{
* Corresponding author. Tel.: +33 5615585 36; fax: +33 561558500.

E-mail addresses: demarez@cesbio.cnes.fr, valerie.demarez@cesbio.cnes.fr (V. Demarez), duthoit@cesbio.cnes.fr (S. Duthoit), baret@avignon.inra.fr (F. Baret), weiss@avignon.inra.fr (M. Weiss), dedieu@cesbio.cnes.fr (G. Dedieu). 0168-1923/\$ - see front matter (c) 2007 Elsevier B.V. All rights reserved. doi:10.1016/j.agrformet.2007.11.015
} 
Jonckheere et al., 2004; Weiss et al., 2004). Non-destructive methods that generally use optical sensors are fast to apply and allow the sampling of large areas. Sensors such as LAI2000 PCA (LI-COR Inc., Nebraska; Welles, 1990) or TRAC (3 ${ }^{\text {rd }}$ Wave Engineering, Ontario, Canada; Leblanc et al., 2002) estimate LAI from light transmittance measurements. Others, such as MVI (Multiband Vegetation Imager; Kucharik et al., 1997) or hemispherical photographs (Rich, 1990; Frazer et al., 2001a), provide canopy gap fraction from image analysis. Digital hemispherical photography is now a very widely used technique (Levy and Jarvis, 1999; Muusche et al., 2001; Frazer et al., 2001b; Jonckheere et al., 2004, 2005; Macfarlane et al., 2007) and a suite of software for processing digital hemispherical photographs are now available: Winscanopy (Regent Instruments, Quebec, Canada), GLA (Forest Renewal BC, Frazer et al., 1999), CIMES (Walter, 1989-2005), CAN_EYE (http:// www.avignon.inra.fr/can_eye) or Hemiview (Delta-T Device). Most of the scientific studies concerning indirect LAI estimation from hemispherical digital photography use methods based on the determination of an optimal threshold (Hemiview, GLA, Winscanopy). Moreover, most of these studies focussed on forest canopies. Despite the performance of new algorithms applied on images to provide automatic classification and optimize LAI estimation, Jonckheere et al. (2005) conclude that new and more complex algorithms might be tested.

The model commonly used with indirect methods to determine the LAI is the Poisson law. It assumes that leaves are uniformly and randomly distributed, which may be valid for homogeneous canopies (Levy and Jarvis, 1999) but does not hold for canopies with aggregative patterns (Nilson, 1971; Lemeur and Blad, 1974; Baldocchi and Collineau, 1994). For such canopies (crops, forest plantations), models based on negative binomial probability functions or on the theory of Markov have been developed (Nilson, 1971; Lemeur and Blad, 1974; Chen and Black, 1992). To allow the use of the Poisson law, the concept of effective LAI is proposed (Chen and Black, 1991; Chen and Cihlar, 1995a; Chen, 1996) which corresponds to the product of a clumping index $(\lambda(\theta))$ with the "true" LAI estimate.

In that context, the recently developed CAN_EYE software is very interesting because it provides not only the effective LAI, but also several estimates of the true LAI. Moreover, pixels are classified interactively in the red/green/blue (RGB) color space that differs from the simple threshold procedure applied on an index or a color (generally the blue). It allows an easier processing of photographs taken from above the canopy, as used for the low canopies (herbaceous or shrubs). In addition, it can be applied to a series of photographs specifically designed to sample the spatial variability of the canopy.
The objective of our study is to determine if the use of a clumping index in the Poisson law is pertinent and if it improves LAI estimates for crops. Effective and true LAI estimated with CAN_EYE are compared with destructive measurements achieved in wheat, maize and sunflower canopies. Measurements were carried out during two growing seasons to capture the seasonal dynamics of the LAI. In addition, the conditions under which photographs were acquired and processed are discussed.

\section{Material and methods}

\subsection{Study site}

The study site is located in the South-West of Toulouse, France $\left(43^{\circ} 30^{\prime} 2^{\prime \prime} \mathrm{N}, 1^{\circ} 14^{\prime} 18^{\prime \prime} \mathrm{E}\right)$. LAI measurements were carried out in 2004 and 2005 over two summer crops (maize and sunflower) and in 2005 over one winter crop (wheat) (Table 1). Canopies were relatively homogeneous as crops were located on flat soil with uniform soil properties and fertilization practices. This allowed us to get comparable LAI values between destructive and photographic methods as their spatial sampling are quite different.

\subsection{Destructive LAI measurements}

Destructive LAI ( $L_{\text {dest }}$ ) was measured during the growing season until maximum canopy development while plants are still green. This maximum matched with the grain filling for wheat, and flowering for maize both in 2004 and 2005. For sunflower, it matched with the seed filling in 2004 and flowering in 2005. As both green stems and leaves are accounted for, the term LAI used in this study corresponds to the green plant area index PAI (Neumann et al., 1989). For wheat (all dates) and for the first dates for maize and sunflower crops, the areas of leaves and young stems were measured with a planimeter (LI-COR 3100; Lincoln Inc., Nebraska). At the two last dates for maize and sunflower, when stems were too large to use planimeter, their developed hemi-surfaces were estimated by measuring the stem height and diameter at half height, assuming that stems were cylinders.

For maize and sunflower, for each date, 15 plants were collected every $10 \mathrm{~m}$ along $150 \mathrm{~m}$ transects to assess the mean area per individual plant. Transects were located in the centre of the field to avoid border effects. Stand destructive PAI $\left(L_{\text {dest }}\right)$ was assessed by multiplying the mean individual plant area by the plant density (plants/ha). For wheat crops, eight plots of $0.5 \mathrm{~m} \times 0.5 \mathrm{~m}$ were harvested along transects. For each plot, a

Table 1 - Main characteristics of the studied crops in 2004 and 2005

$$
\text { Density (plants } / \mathrm{m}^{2} \text { ) }
$$

\begin{tabular}{lc}
\hline Maize 2004 & 7.3 \\
Maize 2005 & 8.0 \\
Sunflower 2004 & 6.1 \\
Sunflower 2005 & 7.3 \\
Wheat 2005 & 173
\end{tabular}

Cultivar 
sub-sample (1/4 of the total sample) was scanned, dried out at $65^{\circ} \mathrm{C}$ for $24 \mathrm{~h}$ and weighed. The remaining $3 / 4$ were similarly dried out and weighed. The plant area was computed by multiplying the dry specific plant area $\left(\mathrm{m}^{2} / \mathrm{g}\right)$ measured on the sub-sample by the plant mass measured over the whole sample.

\subsection{Indirect LAI estimates}

\subsubsection{CAN_EYE software}

The CAN_EYE software computes both the effective LAI and several estimates of the true LAI by adjusting a clumping index (Weiss et al., 2004) based on the Lang and Xiang (1986) averaging method. The main outputs of the software are the clumping index $(\lambda(\theta))$, the effective $\left(L_{\text {eff }}\right)$ and Lang and Xiang $\left(\mathrm{L}_{\mathrm{LX}}\right)$ LAI estimated from the unidirectional gap fraction, and the effective $\left(L_{\text {eff }}\left(57.5^{\circ}\right)\right)$ and Lang and Xiang $\left(L_{\mathrm{LX}}\left(57.5^{\circ}\right)\right)$ LAI estimated from the gap fraction at a $57.5^{\circ}$ zenith angle.

CAN_EYE processes a series of $N$ photographs at ounce, which speeds up the processing time considerably. The gap fraction is calculated from the RGB images through a supervised classification. The original $16,777,216$ colors are reduced to 327 using an automatic classification (Spath, 1985). Contrary to software schemes based on threshold methods which are mainly designed to process upward looking photographs under forests, color schemes exploit downward looking photographs taken over low canopies. CAN_EYE offers several classification options: one can choose to classify the gap pixels only (option 1: non-selected pixels are considered as vegetation), the vegetation pixels only (option 2: non-selected pixels are considered as gaps), both the gaps and vegetation pixels (option 3 ) or else consider more than two classes in order to distinguish flowers, fruits, stems or senescent vegetation for example (option 4). A default classification based on predefined color segmentation is then proposed. However, the classification can be interactively and iteratively refined if judged necessary. When at least two classes are considered (options 3 and 4), CAN_EYE manages mixed pixels: non-selected pixels are assumed to be mixed pixels and they are then automatically classified in one or the other class depending on the location of the pixel in the color space.

Additionally, CAN_EYE uses a tool to mask areas to eliminate parts of the photographs contaminated by undesirable objects (feet of the photographer, sun glint, etc.) which are often present when acquiring downward images.

The version 4.0 of CAN_EYE was used for this work.

\subsection{Effective LAI estimation}

Hemispherical photographs are divided into angular sectors with respective zenith $(\Delta \theta)$ and azimuth angular $(\Delta \varphi)$ resolutions defined by the user. After tests showing the little sensitivity of $L_{\text {eff }}$ to the $[\Delta, \Delta \varphi]$ parameters, default values were finally kept $\left(\Delta \theta=2.5^{\circ}\right.$ and $\left.\Delta \varphi=5^{\circ}\right)$. After the classification process, the gap fraction $P_{\mathrm{O}, \mathrm{CAN}_{-} E Y E}(\theta)$ is computed for each zenithal ring $\theta$ by averaging over the $N$ photographs and the 72 azimuth sectors excluding masked pixels. Masked areas are accounted for by weighting the $P_{\mathrm{O}, \mathrm{CAN} \_ \text {EYE }}(\theta)$ values of each sector by the ratio of unmasked pixels to the total number of pixels.

$L_{\text {eff }}$ is computed from the gap fraction $P_{\mathrm{O}, \text { CAN_EYE }}(\theta)$ following the Poisson law (Monsi and Saeki, 1953; Welles and Norman, 1991) (Eq. (1)):

$P_{\mathrm{O}, \mathrm{CAN} \_\mathrm{EYE}(\theta)}=\frac{\exp \left(-\mathrm{L}_{\text {eff }} G\left(\theta, \varphi, \theta_{\text {leaf,eff }}\right)\right.}{\cos \theta}$

where $\theta$ and $\varphi$ are respectively the zenith and azimuth angles of the direction of propagation of the incident beam, $L_{\text {eff }}$ refers to effective LAI, $G(\theta, \varphi)$ is the mean projection of a leaf area unit in a plane perpendicular to direction $(\theta, \varphi)$ which is directly dependent of the leaf angle distribution (LAD). LAD is assumed to be uniform in azimuth and following an ellipsoidal distribution for the inclination (Campbell, 1986, 1990; Wang and Jarvis, 1988). It is thus fully characterized with the average leaf angle (ALA) only. Two variables are therefore needed to describe canopy architecture under these assumptions: the effective LAI ( $\left.L_{\text {eff }}\right)$ and effective ALA ( $\left.\theta_{\text {leaf,eff }}\right)$.

A look-up-table (LUT) is used to estimate $L_{\text {eff }}$ and $\theta_{\text {leaf,eff }}$ from the measured zenithal variation of the gap fraction (Weiss et al., 2004) as an alternative to the Miller's formula (Miller, 1967). The LUT is built by combining $L_{\text {eff }}$ values between $0^{\circ}$ and $10^{\circ}$ (by $0.01^{\circ}$ steps), and $\theta_{\text {leaf,eff }}$ values between $10^{\circ}$ and $80^{\circ}$ (by $2^{\circ}$ steps). A cost function $J$ (Eq. (2)), representing the distance between measured and simulated gap fractions values, is evaluated over the 36,036 [ $\left.L_{\text {eff }}, \theta_{\text {leaf,eff }}\right]$ pairs:

$$
\begin{aligned}
& J=
\end{aligned}
$$

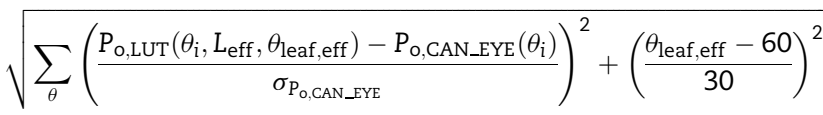

where $P_{\mathrm{O}, \mathrm{CAN} \_ \text {EYE }}\left(\theta_{i}\right)$ is the measured gap fraction derived from CAN_EYE, $P_{\text {o,LUT }}\left(\theta_{\mathrm{i}}, L_{\text {eff }}, \theta_{\text {leaf,eff }}\right)$ is the gap fraction stored in the LUT and $\rho_{\text {Po,CAN_EYE }}$ is the standard deviation of the CAN_EYE measured gap fraction. The second term on the right-hand side of Eq. (2) imposes constraints on the retrieved $\theta_{\text {leaf,eff }}$ values and regularizes the sometimes ill-posed nature of this inverse problem (Combal et al., 2002). The solution is the value of [ $\left.L_{\text {eff }}, \theta_{\text {leaf,eff }}\right]$ that minimizes the cost function $J$.

Effective leaf area index calculated at the $57.5^{\circ}$ zenith angle $L_{\text {eff }}\left(57.5^{\circ}\right)$ is computed following equation (Weiss et al., 2004):

$L_{\text {eff }}\left(57.5^{\circ}\right)=-\frac{\log \left(P_{\mathrm{O}, \text { CAN_EYE }}\left(57.5^{\circ}\right)\right)}{0.93}$

where $P_{\mathrm{O}, \text { CAN_EYE }}\left(57.5^{\circ}\right)$ is computed within $56-59^{\circ}$ zenith angles.

For this particular direction, $G(\theta, \varphi)$ (Eq. (1)) is almost independent of leaf inclination (Warren-Wilson, 1963) simplifying the LAI retrieval process.

\subsection{LAI estimates accounting for leaf clumping}

$\mathrm{L}_{\mathrm{LX}}$ refers to the LAI calculated using the Lang and Xiang (1986) method of averaging gap fractions. This approach assumes that vegetation elements are locally randomly distributed. 
Each zenithal ring is divided into cells of $2.5^{\circ}$ in zenith and $4^{\circ}$ in azimuth. The gap fraction $P_{\mathrm{o}, \text { cell }}(\theta)$ is computed for each cell following the modified Poisson law (Eq. (4)):

$P_{o, \text { cell }}(\theta)=\frac{\exp \left(-\lambda_{\mathrm{LX}}\left(\theta, \theta_{\text {leaf,eff }}\right) \mathrm{L}_{\mathrm{LX}} G\left(\theta, \varphi, \theta_{\text {leaf }, \mathrm{LX}}\right)\right.}{\cos \theta}$

$P_{\mathrm{o}, \text { cell }}(\theta)$ is averaged over azimuth and photographs for each zenithal ring. The averaging takes into account the masked areas. The clumping index $\lambda_{\mathrm{LX}}\left(\theta, \theta_{\text {leaf,eff, }} \mathrm{P}_{\mathrm{o}, \text { cell }}\right)$ is defined as

$\lambda_{\mathrm{LX}}\left(\theta, \theta_{\text {leaf }, \text { eff }}\right)=\frac{\operatorname{mean}\left(\log \left(P_{\mathrm{o}, \text { cell }}(\theta)\right)\right)}{\log \left(\operatorname{mean}\left(P_{\mathrm{o}, \text { cell }}(\theta)\right)\right)}$

Note that since $P_{\mathrm{o}, \text { cell }}(\theta)$ depends on $\theta_{\text {leaf,eff, the clumping }}$ index is computed for the whole range of variation of $\theta_{\text {leaf,eff. }}$ Then the same algorithm, as described previously for $L_{\text {eff }}$, is applied. A LUT is built using the modified Poisson law (Eq. (4)) to provide $L_{\mathrm{LX}}, \theta_{\text {leaf,LX }}$ as well as the corresponding clumping index $\lambda_{\mathrm{LX}}\left(\theta, \theta_{\text {leaf,eff }}\right)$.

For cells completely obstructed by vegetation with no gaps $\left(P_{o}=0\right.$, which theoretically leads to LAI $\left.=\infty\right), P_{o}$ is assumed to be equal to $P_{o, \text { sat }}$ derived from Eq. (1) with $\theta_{\text {leaf,eff }}$ and a prescribed $L_{\text {sat }}$ value $(=10)$.

\subsection{Photography}

Hemispherical photographs were taken in jpeg format at the highest possible resolution $(2272 \times 1704$ pixels $)$ with a Nikon CoolPix 4500 equipped with the FC-E8 fisheye lens (focal length $\times 0.21$ ). The camera was calibrated using the method described in http://www.avignon.inra.fr/can_eye to compute the optical centre of the "camera-fisheye lens" system.

Photographs were taken every $10 \mathrm{~m}$ along transects before destructive measurements. A total of 14 photographs were taken per transect in order to get a reliable measurement of the gap fraction (Weiss et al., 2004).

The camera was maintained in an approximately horizontal position ( $\pm 3^{\circ}$ estimated from the location of the horizon in the image over flat terrains). Sensitivity analysis demonstrated that the process can tolerate some degree of inaccuracy in leveling the camera in estimating LAI $\left(10^{\circ}\right.$ uncertainty in camera level, see results on http://www.avignon.inra.fr/can_eye). The camera was set to automatic exposure to prevent saturation unlike the advice of Zhang et al. (2005). Zhang et al. (2005) focused on upward oriented black and white images and simple grey level threshold while CAN_EYE treats colored images possibly taken from above the canopy. In that case, automatic exposure provided visually

Table 2 - From the left to right columns: type of crops, dates of destructive and photographic measurements, phenological stages (LD: leaf development; II: inflorescence initialisation; FL: flowering; GF: grain filling; SF: seed filling), canopy heights $(H)$, destructive LAI ( $\left.L_{\text {dest }}\right)$, CAN_EYE effective LAI $\left(L_{\text {eff }}\right)$ estimated from the directional and $57.5^{\circ}$ gap fractions, CAN_EYE LAI estimated using the Lang and Xiang method $\left(L_{L x}\right)$ from the directional and $57.5^{\circ}$ gap fractions, camera orientation (down: downward; up: upward) and illumination conditions during the photographic acquisitions (Sky)

\begin{tabular}{|c|c|c|c|c|c|c|c|}
\hline Dates & Pheno. & $H(\mathrm{~m})$ & $L_{\text {dest }}$ & $L_{\text {eff }}\left(L_{\text {eff }}\left(57.5^{\circ}\right)\right)$ & $L_{L X}\left(L_{L X}\left(57.5^{\circ}\right)\right)$ & Config. & Sky \\
\hline \multicolumn{8}{|l|}{ Wheat 2005} \\
\hline 21 January 2005 & LD & 0.07 & 0.11 & $0.20(0.18)$ & $0.19(0.18)$ & Down & Overcast \\
\hline 09 February 2005 & LD & 0.07 & 0.19 & $0.10(0.13)$ & $0.15(0.14)$ & Down & Overcast \\
\hline 04 March 2005 & LD & 0.1 & 0.27 & $0.30(0.32)$ & $0.33(0.33)$ & Down & Overcast \\
\hline 01 April 2005 & LD & 0.17 & 1.03 & $1.00(0.94)$ & $1.01(0.98)$ & Down & Sunny \\
\hline 14 April 2005 & LD & 0.30 & 2.63 & $2.60(2.22)$ & $3.03(2.94)$ & Down & Sunny \\
\hline 04 May 2005 & II & 0.55 & 3.36 & $3.00(2.73)$ & $3.25(2.99)$ & Down & Overcast \\
\hline 11 May 2005 & GF & 0.66 & 3.43 & $3.40(3.29)$ & $4.18(4.21)$ & Up/down & Overcast \\
\hline \multicolumn{8}{|l|}{ Maize 2004} \\
\hline 24 June 2004 & LD & 0.50 & 0.45 & $0.40(0.38)$ & $0.6(0.71)$ & Down & Overcast \\
\hline 06 July 2004 & LD & 1.00 & 1.98 & $0.90(0.91)$ & $1.37(1.74)$ & Up/down & Overcast \\
\hline 22 July 2004 & LD & 1.80 & 3.77 & $2.50(2.44)$ & $3.30(3.9)$ & Up & Sunny \\
\hline 03 August 2005 & $\mathrm{FL}$ & 2.00 & 3.84 & $2.90(2.75)$ & $3.46(4.14)$ & Up & Sunny \\
\hline \multicolumn{8}{|l|}{ Maize 2005} \\
\hline 07 June 2005 & LD & 0.50 & 0.95 & $0.70(0.70)$ & $0.82(1.19)$ & Down & Overcast \\
\hline 22 June 2005 & LD & 0.50 & 3.19 & $2.30(2.25)$ & $3.25(3.68)$ & Up & Sunny \\
\hline 05 July 2005 & FL & 1.96 & 5.06 & $3.40(3.43)$ & $4.55(4.81)$ & Up & Sunny \\
\hline \multicolumn{8}{|l|}{ Sunflower 2004} \\
\hline 27 May 2004 & LD & 0.17 & 0.34 & $0.30(0.24)$ & $0.85(0.4)$ & Down & Overcast \\
\hline 16 June 2004 & II & 0.71 & 1.20 & $0.50(0.51)$ & $0.69(0.92)$ & Down & Overcast \\
\hline 08 July 2004 & FL & 1.00 & 1.39 & $0.90(0.95)$ & $1.73(2.03)$ & Up & Cloudy \\
\hline 22 July 2004 & SF & 1.00 & 1.22 & $0.90(0.97)$ & $2.09(2.12)$ & Up & Sunny \\
\hline \multicolumn{8}{|l|}{ Sunflower 2005} \\
\hline 25 May 2005 & LD & 0.49 & 0.85 & $0.80(0.72)$ & $1.72(1.52)$ & Down & Sunny \\
\hline 07 June 2005 & LD & 1.00 & 2.80 & $2.70(2.20)$ & $4.04(3.54)$ & Up/down & Sunny \\
\hline 22 June 2005 & FL & 1.47 & 2.92 & $2.50(2.52)$ & $3.97(3.78)$ & Up & Sunny \\
\hline
\end{tabular}

At the end of the growing season, stems contributed to about $12 \%$ of PAI in sunflower and maize, and $22 \%$ in wheat. 

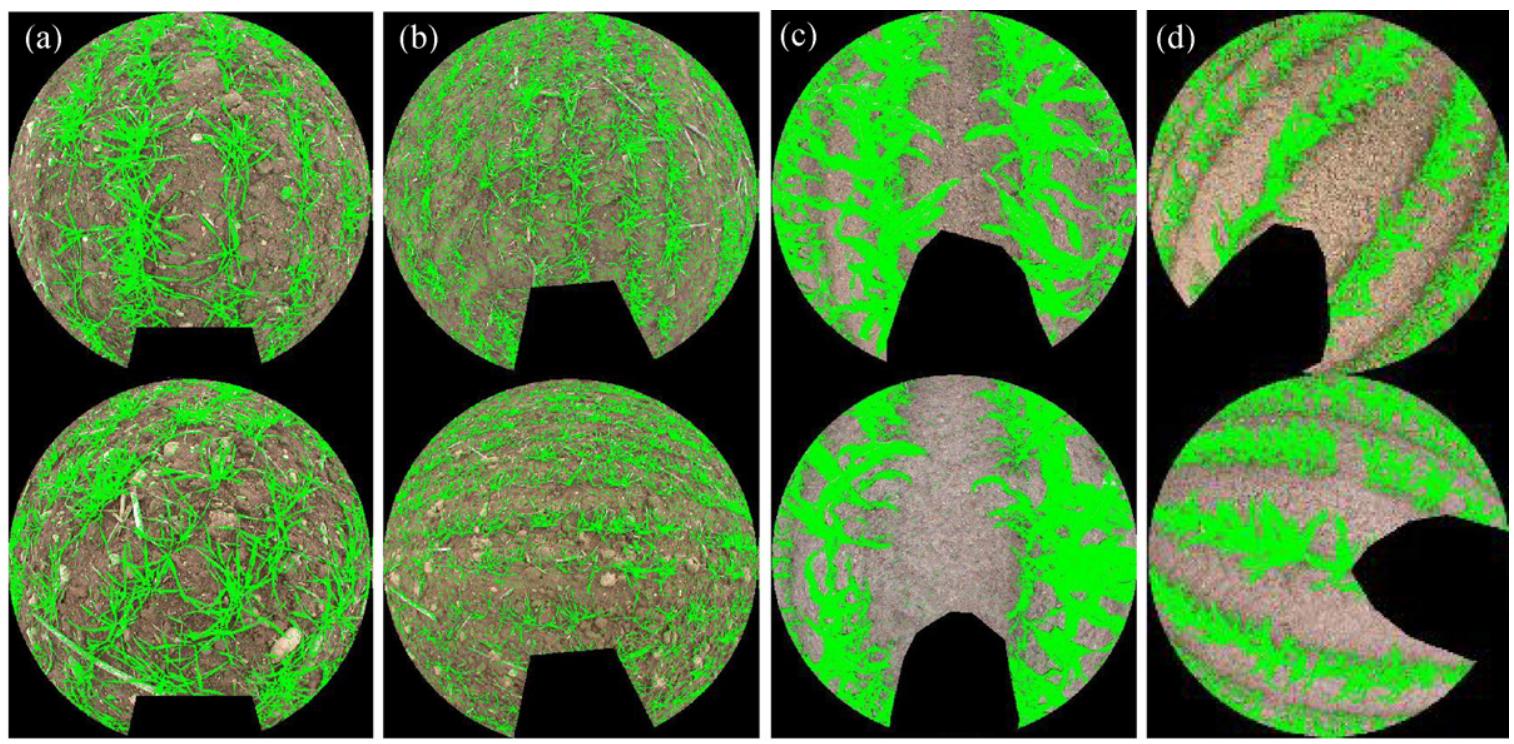

Fig. 1 - Examples of CAN_EYE classifications of images in wheat on 4 March 2005 (a and b) and maize on 7 July 2005 (c and d) at (a and c) $0.40 \mathrm{~m}$ and (b and d) $1 \mathrm{~m}$ canopy to sensor distances. Black areas on the classifications correspond to masked area (feet of photographer). Photographs taken at the largest distance $(1 \mathrm{~m})$ from canopies cover wider area of the field (higher number of rows).
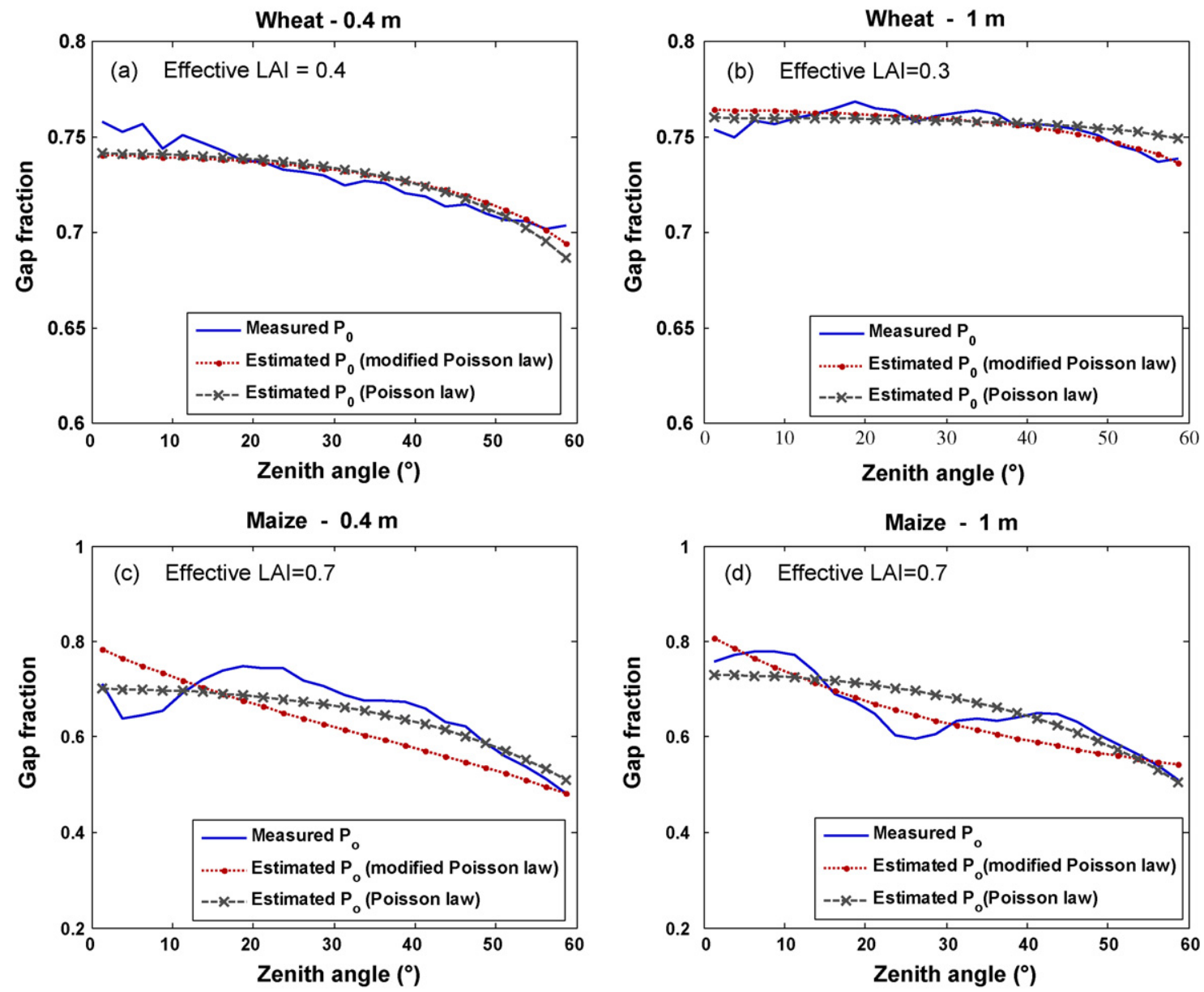

Fig. 2 - Gap fractions $\left(P_{o}(\theta)\right)$ vs. zenith angle $\left({ }^{\circ}\right)$ measured in wheat (a and b) and maize (c and d) canopies with photographs taken at $0.40 \mathrm{~m}$ ( $a$ and $c$ ) and $1 \mathrm{~m}(\mathrm{~b}$ and $\mathrm{d})$. Differences observed in $P_{0}(\theta)$ do not automatically induce differences of effective LAI estimates such as in maize. 
good quality photographs allowing easy and accurate pixel classification.

For low canopies (less than $0.6 \mathrm{~m}$ high) with small leaves, the camera was oriented downwards. The distance between the objective and the top canopy was set to $1 \mathrm{~m}$ to avoid having individual leaves too close from the sensor. However, to assess the effect of the camera to canopy distance on LAI determination, two distances were tested: 0.40 and $1 \mathrm{~m}$. For tall canopies
$(>1 \mathrm{~m})$ with larger leaves, the camera was placed at ground level looking upward. In that case, care was taken not to modify the canopy structure when positioning the camera on the ground. For intermediate canopy heights (between 0.6 and $1 \mathrm{~m}$ height), both upwards and downwards images are usually feasible without being too close from the leaves. That is why both downward and upward looking photographs were taken at a few dates (Table 2) in order to investigate the effect of
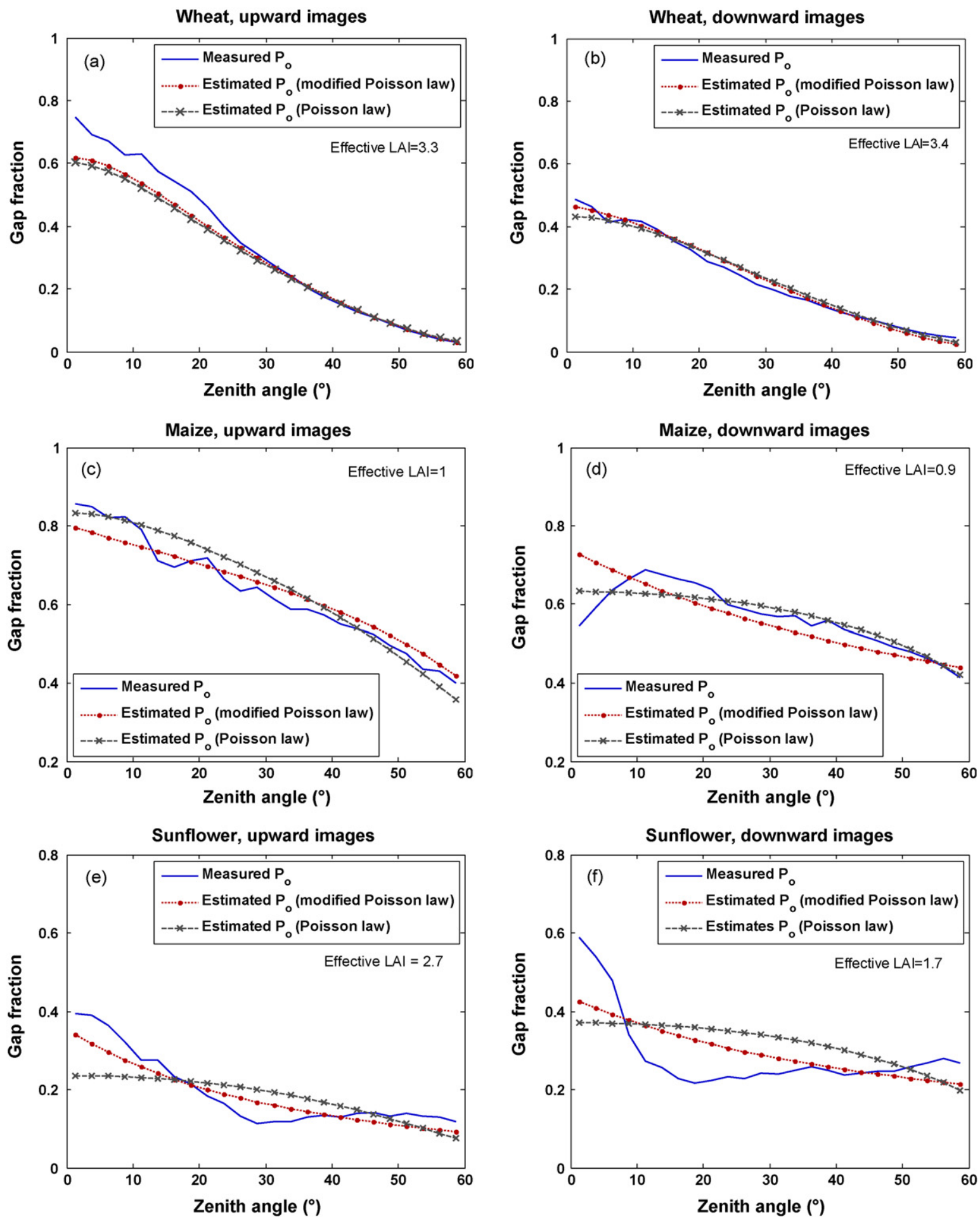

Fig. 3 - Gap fractions $\left(P_{\circ}(\theta)\right)$ vs. zenith angle ( $\left.{ }^{\circ}\right)$ measured in wheat (11 May 2005), maize (6 July 2004$)$ and sunflower (7 June 2005) canopies with (a, c and e) upward and (b, $d$ and f) downward photographs. 
these two configurations of acquisition on the gap fraction estimates.

In all series of photographs, the processing was restricted to view zenith angles smaller than $60^{\circ}$ in view of limiting the proportion of mixed pixels.

Finally, for each crop and for both upward and downward looking photographs, two classification methods were tested which consist in either classifying soil only or vegetation only. In upward looking photographs both classifications lead to very similar gap fractions and LAI estimates. In downward looking photographs, classifying leaves only (option 2) leads to more precise classifications. Indeed, when classifying soil only (option 1), shadowed parts were automatically classified as leaves leading to underestimates of gap fractions. Thus leaves classification (option 2) was adopted in downwards photographs while sky classification (option 1) was adopted in upwards photographs.

\section{Results and discussion}

The constraints and opportunities offered by the protocol of photographic acquisition for gap fraction estimation and effective LAI retrieval $\left(L_{\text {eff }}\right)$ are first presented and analyzed. Then, the different CAN_EYE LAI estimates are compared with destructive LAI values.

\subsection{Spatial sampling: canopy to camera distance}

Series of downward looking photographs were acquired over wheat (4 March 2005) and maize (7 June 2005) canopies for short $(0.40 \mathrm{~m})$ and large $(1 \mathrm{~m})$ distance from canopy (Fig. 1).

For wheat, differences are observed on measured and modelled $\mathrm{P}_{\mathrm{o}}(\theta)$ (Fig. 2a and b). For images taken at $1 \mathrm{~m}$ above the canopy, the decrease of the gap fraction with $\theta$ is lesser due to a larger soil contribution in relation to a larger spatial representativeness. This leads to a discrepancy between $L_{\text {eff }}$ values of 0.4 at $0.4 \mathrm{~m}$ distance and 0.3 at $1 \mathrm{~m}$ distance.

For maize, despite differences observed of the measured gap fraction with angular variations (Fig. $2 c$ and d), the $L_{\text {eff }}$ values are similar $\left(L_{\text {eff }}=0.70\right)$ due to very close modelled gap fractions. However, $P_{\mathrm{o}}(\theta)$ measured from $1 \mathrm{~m}$ above canopy should provide better LAI estimate because of a wider spatial sampling (Fig. 1). We can finally notice that even with a $1 \mathrm{~m}$ distance, angular variations due to row effects are strong (Fig. 2d).

\subsection{Upward or downward looking photographs}

Upward and downward looking photographs were simultaneously acquired over wheat (11 May 2005), maize (6 July 2004) and sunflower (7 June 2005) canopies. Canopy heights were $0.66 \mathrm{~m}$ for wheat and $1 \mathrm{~m}$ for maize and sunflower (Fig. 3). In downwards configurations the camera to canopy distance was set to $1 \mathrm{~m}$, as specified previously in the methodology section.

For maize and wheat, the upward looking $P_{o}(\theta)$ values (Fig. 3a and c) are greater than those measured in the downward looking configuration (Fig. $3 b$ and d). In fact, in the upward configuration, the spatial sampling is narrower and highlights the inter-rows contribution, increasing the gap (sky) fraction. However, in both cases, quite similar $L_{\text {eff }}$ values are obtained despite differences observed in the measured $P_{\circ}(\theta)$, because of the compensations between $L_{\text {eff }}$ and $G(\theta, \varphi, \theta-$ leaf,eff) during the inversion procedure. Indeed, for wheat, $\theta_{\text {leaf,eff }}$ is $80^{\circ}$ with upwards photographs and $74^{\circ}$ with downwards ones. For maize, $\theta_{\text {leaf,eff }}$ is $78^{\circ}$ with upwards photographs and $58^{\circ}$ with downwards ones. As downwards photographs cover larger field of views (Fig. 1) and are thus more spatially representative than upwards ones, they are expected to provide more accurate $P_{\circ}(\theta)$ measurements even if our results show no differences in $L_{\text {eff. }}$.

For sunflower, the gap fraction measured from the upward configuration is inferior to the downward one (Fig. 3e and $f$ ) leading to $L_{\text {eff }}$ values of 2.7 and 1.7 , respectively. The downwards photographs were taken on a sunny day inducing strong shadow effects that render the image classification tricky: some of the pixels occupied by shaded leaves were classified as soil, leading to an underestimation of the measured gap fraction.

These results highlight the importance of both camera orientation and illumination condition on the gap fraction measurements and thus on LAI estimates. Downward configuration allows in theory a wider spatial representativeness but can also lead to poor gap fraction estimates under sunny illumination conditions. When feasible, both downward looking and overcast condition should be privileged.

\subsection{Comparison between destructive and CAN_EYE LAI estimates}

3.3.1. $L_{\text {eff }}$ derived from the directional variation of $P_{o}(\theta)$ $L_{\text {eff }}$ and $L_{\text {dest }}$ for all crops over the 2 years (Table 2 and Fig. 4) are strongly correlated (root mean square error, RMSE $=0.63$ and correlation coefficient, $r=0.95$ ). However there is a systematic skew ( $y=0.7810 x$, Fig. 4$)$ that leads to the well-known LAI underestimation with $L_{\text {eff }}$ in clumped canopies. The highest

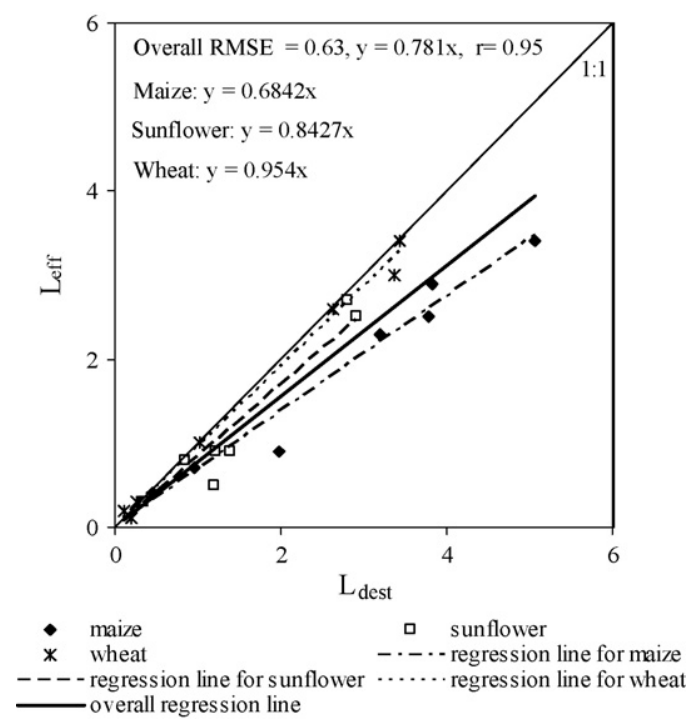

Fig. 4 - Plot of effective ( $\left.L_{\text {eff }}\right)$ vs. destructive $\left(L_{\text {dest }}\right)$ LAI estimates for the three crops in 2004 and 2005. The overall root mean square error (RMSE) and correlation coefficient $(r)$ are given. The overall regression line and the regression lines for each crop are drawn. 
value of the skew is encountered in maize $(y=0.6842 x$, RMSE $=1.02$, Fig. 4) and the lowest in wheat $(y=0.9540 x$, RMSE $=0.15$, Fig. 4). Intermediate value is assessed in sunflower $(y=0.8427 x$, RMSE $=0.38$, Fig. 4). However, differences exist between crops and stages of canopy development.

For sunflower, differences exist between the 2 years. Indeed, the skew is particularly strong in 2004 with LAI underestimated by about $40 \%(y=0.6135 x)$, whereas it is only underestimated by about $10 \%$ in $2005(y=0.9094 x)$. In 2004, contrary to other crops, sunflower was affected by a drought explaining the low values of LAI (maximum LAI of 1.4). Thus, in 2004, the sunflower canopy remained open till the maximum canopy development.

For wheat, there is a good agreement between $L_{\text {eff }}$ and $L_{\text {dest }}$ estimates except for the two first dates of canopy development (21 January and 9 February, LAI $<0.2$ ) where the differences between $L_{\text {eff }}$ and $L_{\text {dest }}$ exceed $50 \%$.

(a)

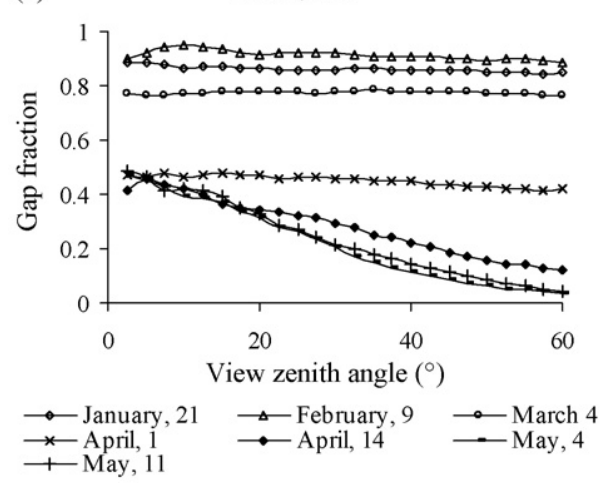

For maize, the skew is quite similar both in 2004 and 2005 ( $y=0.6808 x$ and $y=0.6871 x$, respectively).

The gap fraction variations with zenith angle for wheat, maize and sunflower are further investigated and analyzed both in 2004 and 2005 (Fig. 5). For the three first dates of wheat (21 January, 9 February, 4 March), $P_{\circ}$ does not decrease with $\theta$, explaining the poor LAI prediction at the beginning of the growing season. From April to May, $P_{\mathrm{o}}$ decreases monotonically with $\theta$ in agreement with the Poisson law. The same applies for maize at the latest development stages ( 6 and 22 July and 3 August in 2004 and 22 June and 5 July in 2005). The use of a modified Poisson law is then expected to correct the effective LAI underestimation observed on maize. On the contrary, at the first stage for maize (4 June in 2004 and 7 June in 2005) and at all dates for sunflower, $\mathrm{P}_{\mathrm{o}}(\theta)$ does not decrease monotonically with $\theta$ due to row effects.

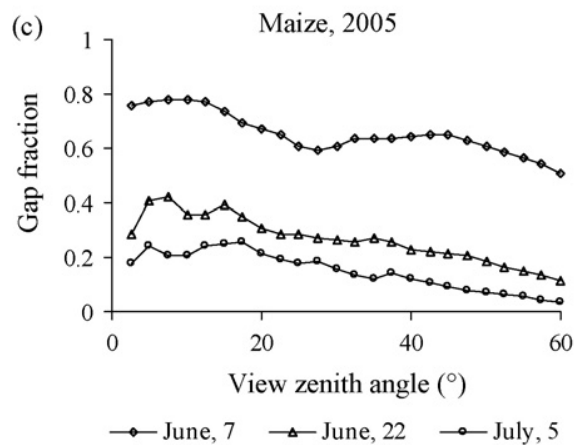

(b)

Maize, 2004
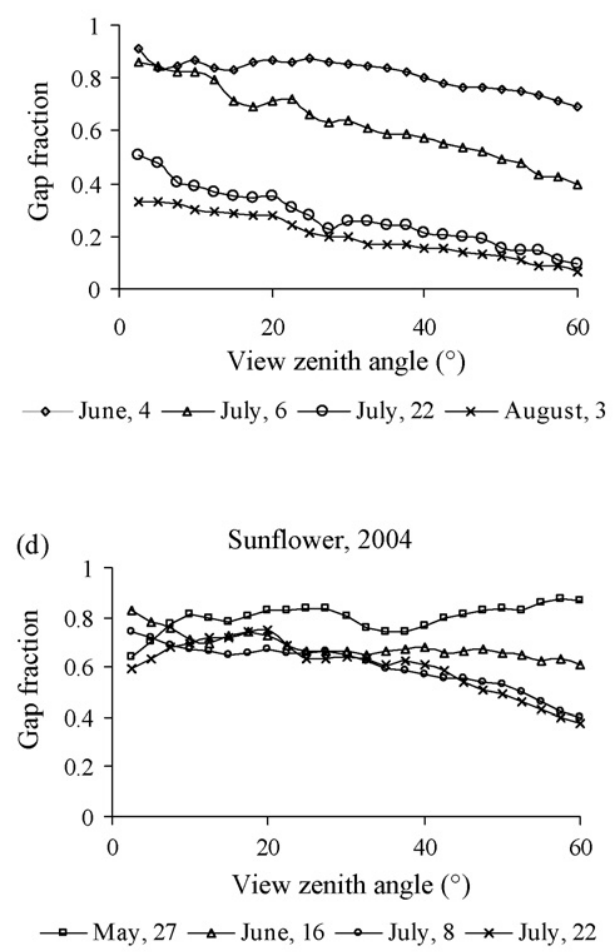

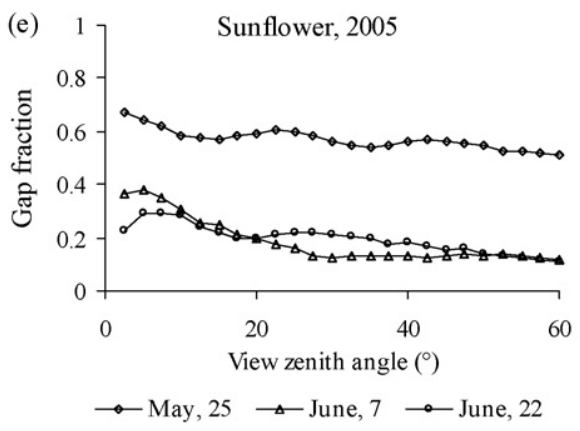

Fig. 5 - Variations of the gap fraction with zenith angle measured in wheat, maize and sunflower in 2004 and 2005. The exponential variation with zenith angle modelled by the Poisson law is only observed for matures stands of wheat (from 14 April to May) and maize (July and August 2004; 22 June and July 2005). 


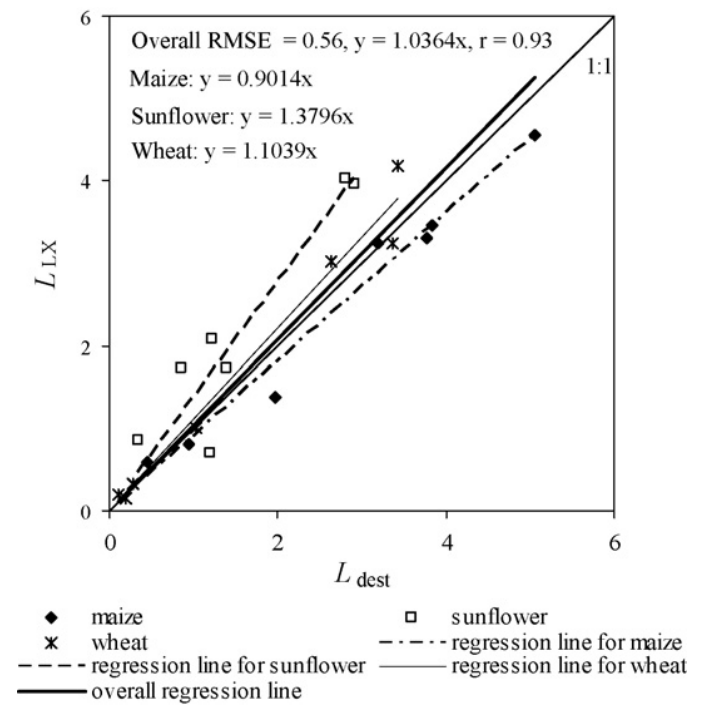

Fig. 6 - Plot of Lang and Xiang $\left(L_{\mathrm{LX}}\right)$ vs. destructive $\left(\mathrm{L}_{\text {dest }}\right) \mathrm{LAI}$ estimates for the three crops in 2004 and 2005. The overall root mean square error (RMSE) and correlation coefficient (r) are given. The overall regression line and the regression lines for each crop are drawn.

\subsection{Accounting for leaf clumping}

The use of the modified Poisson law seems to improve globally LAI estimates (overall RMSE $=0.56$ and $y=1.0364 x$ instead of 0.63 and $y=0.781 x$ with $L_{\text {eff }}$, Fig. 6). However, differences are

(a)

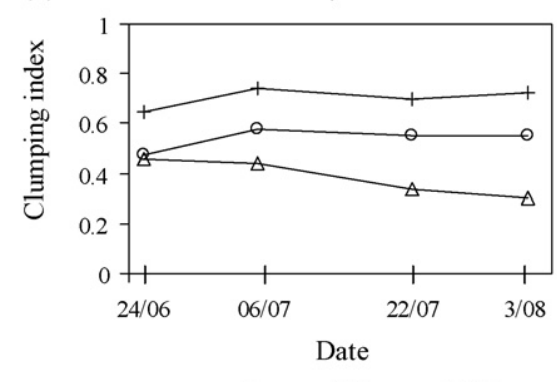

observed between crops. For maize, the use of the clumping index decreases the underestimation observed with $L_{\text {eff }}$ from $32 \%(y=0.6842 x, \operatorname{RMSE}=1.02)$ to $10 \%(y=0.9014 x, \operatorname{RMSE}=0.39)$. This result was expected at the latest stages of canopy development as $P_{0}$ monotonically decreased with $\theta$ (Fig. 5). The use of the modified Poisson law gives also better LAI estimates at the first stage of canopy development in 7 June 2005 (Table 2), in spite of the discontinuous variations of $P_{0}$ with zenith angles due to row effects (Fig. 5).

For wheat and sunflower, LAI estimates are not globally improved by the use of the modified Poisson law (RMSE $=0.33$ instead of 0.15 in wheat and 0.83 instead of 0.38 in sunflower) except for few dates corresponding to the first stages of canopy development. Indeed, in sunflower, LAI estimates are improved on 16 June and 8 July 2004 even if mean relative differences between $L_{\text {dest }}$ and $L_{\text {eff }}$ remain still high (42\% and $25 \%$, respectively, Table 2). The same occur for wheat on February $\left(9^{\text {th }}\right)$ (Table 2). At the other dates, the use of a clumping index leads to a large overestimation of the LAI $(y=1.1039 x$ for wheat and $y=1.3796 x$ for sunflower, Fig. 6) that may reach $100 \%$ for sunflower (25 May 2005). For wheat, at the first date (21 January), the Lang and Xiang LAI estimates $\left(L_{\mathrm{LX}}\right)$ is surprisingly inferior to $L_{\text {eff. }}$ This result may reveal that the limit of validity of the inversion procedure is reached because of too low LAI values.

\subsection{Analysis of validity of $\lambda_{\mathrm{LX}}$ and $\theta_{\text {leaf,eff }}$ estimates for maize canopy}

As the modified Poisson law improves significantly LAI estimates for maize, the seasonal changes of $\lambda_{\mathrm{LX}}, \theta_{\text {leaf,eff }}$ and

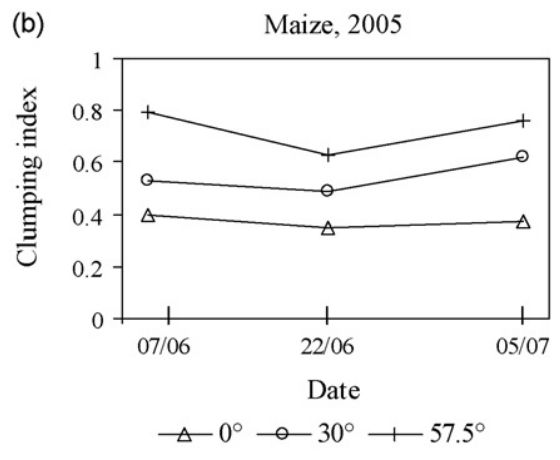

Fig. 7 - Seasonal variation of the clumping index estimated by CAN_EYE on maize in (a) 2004 and (b) 2005 for three zenith angles $\left(0^{\circ}, 30^{\circ}\right.$ and $\left.57.5^{\circ}\right)$.

(a)

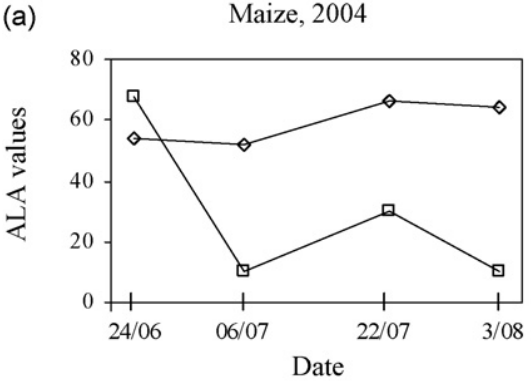

$\multimap$ Effective ALA $\rightarrow$ Lang and Xiang ALA (b)

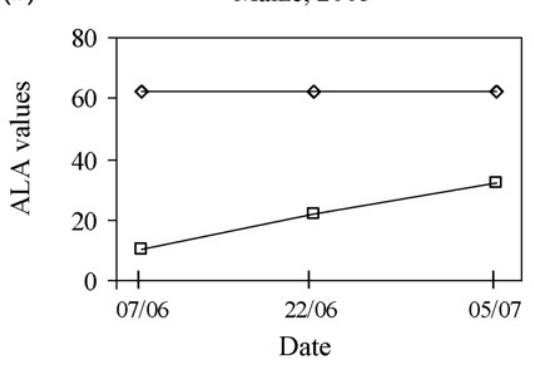

$\multimap$ Effective ALA $\rightarrow$ Lang and Xiang ALA

Fig. 8 - Seasonal variation of effective $\left(\theta_{\text {leaf,eff }}\right)$ and Lang and Xiang $\left(\theta_{\text {leaf,LX }}\right)$ average leaf angle (ALA) estimated by CAN_EYE on maize in (a) 2004 and (b) 2005. 


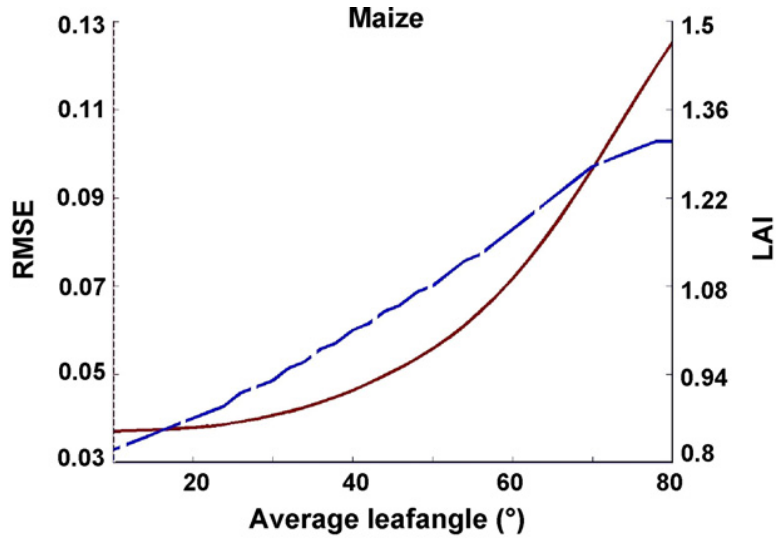

Fig. 9 - Results of CAN_EYE processing carried out on maize on 7 June 2005. The root mean square errors (RMSE) (continuous line) between modelled (modified Poisson law) and measured gap fractions are plotted as a function of Lang and Xiang average leaf inclination angle ( $\left.\theta_{\text {leaf,Lx }}\right)$. The Lang and Xiang leaf area index estimations $\left(L_{L X}\right.$, dashed line) are also reported.

$\theta_{\text {leaf,Lx }}$ estimated in 2004 and 2005, were further analyzed (Figs. 7 and 8). As expected, $\lambda_{\text {LX }}$ (Fig. 7) increases with $\theta$ but does not increase during the growing season as could be expected from the canopy closure. $\theta_{\text {leaf,eff }}$ (ALA) remains quite constant during the season around $60^{\circ}$ during the 2 years (Fig. 8), matching with the spherical distribution measured by España et al. (1999). On the contrary, $\theta_{\text {leaf,Lx }}$ is very variable in 2004 (Fig. 8a) and increases progressively from $10^{\circ}$ to $30^{\circ}$ in 2005 (Fig. 8b). In a robust procedure inversion, the $\theta_{\text {leaf,Lx }}$ and $\theta_{\text {leaf,eff }}$ values should be identical. Large discrepancies between $\theta_{\text {leaf,LX }}$ and $\theta_{\text {leaf,eff }}$ suggest that some compensation between $G\left(\theta, \theta_{\text {leaf }}\right.$ $\mathrm{LX}$ ) and $\mathrm{L}_{\mathrm{LX}}$ occurs during the inversion process. The analysis of the cost function $J$ (Eq. (2)) computed for maize on 7 June 2005 (Fig. 9), in which $P_{\circ}(\theta)$ does not decrease monotonically with $\theta$ but LAI estimates is finally improved, corroborates this assumption. Indeed, the minimum RMSE value is obtained for the smallest $\theta_{\text {leaf,LX }}$ value $\left(10^{\circ}\right)$ in the LUT (Fig. 9), suggesting a planophil leaf distribution that is in disagreement with field observations (Antunes et al., 2001; España et al., 1999).

The application into CAN_EYE of the Lang and Xiang method is thus investigated. As written previously, the $\lambda_{\mathrm{LX}}$ (Eq. (5)) is computed for a cell size of $2.5^{\circ}$ by $4^{\circ}$. To apply the Lang and Xiang method, the size of the cells must verify two

Table 3 - CAN-EYE leaf area index $\left(L_{L X}\right)$ and average leaf angle $\left(\theta_{\text {leaf,Lx }}\right)$ estimated on maize from the modified Poisson law for different cell sizes

\section{Cells size}

\begin{tabular}{|c|c|c|c|c|c|c|}
\hline & \multicolumn{2}{|c|}{$2.5^{\circ} \times 4^{\circ}$} & \multicolumn{2}{|c|}{$5^{\circ} \times 8^{\circ}$} & \multicolumn{2}{|c|}{$10^{\circ} \times 16^{\circ}$} \\
\hline & $\mathrm{L}_{\mathrm{LX}}$ & $\theta_{\text {leaf,LX }}\left({ }^{\circ}\right)$ & $L_{L X}$ & $\theta_{\text {leaf,Lx }}\left({ }^{\circ}\right)$ & $L_{\mathrm{LX}}$ & $\theta_{\text {leaf,LX }}\left({ }^{\circ}\right)$ \\
\hline \multicolumn{7}{|l|}{ Maize 2005} \\
\hline 22 June & 2.94 & 22 & 3.45 & 42 & 3.35 & 48 \\
\hline 5 July & 4.74 & 42 & 5.21 & 48 & 5.06 & 56 \\
\hline
\end{tabular}

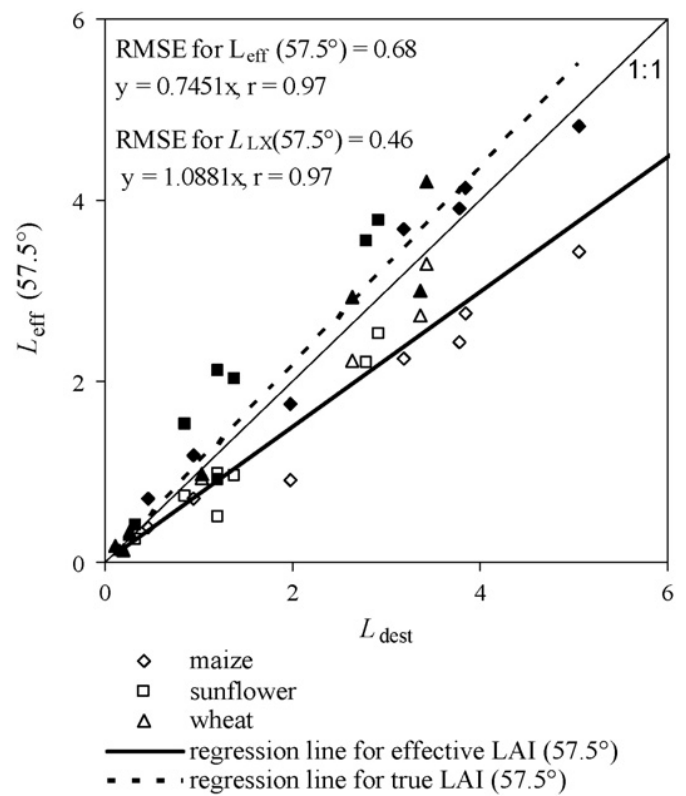

Fig. 10 - Plot of effective $\left(L_{\text {eff }}\left(57.5^{\circ}\right)\right)$ and Lang and Xiang $\left(\mathrm{L}_{\mathrm{LX}}\left(57.5^{\circ}\right)\right) \mathrm{LAI}$ estimated from gap fractions at $57.5^{\circ} \mathrm{vs.}$ destructive LAI ( $\left.L_{\text {dest }}\right)$ for the three crops in 2004 and 2005. The overall root mean square errors (RMSE) and correlation coefficients $(r)$ are given. The overall regression line is drawn.

criteria: it should be large enough so that the statistics of the gap fraction are meaningful, and small enough for the assumption of randomness of leaf distribution within cell to hold. The sensitivity of $\mathrm{L}_{\mathrm{LX}}$ estimates to cell size is investigated at two dates (22 June and 5 July 2005). CAN-EYE LAI and $\theta_{\text {leaf,LX }}$ estimates vary according to the size of the cells (Table 3 ). The best LAI estimates are obtained with the larger cell size $\left(10 \times 16^{\circ}\right)$ (see Table 2 for $L_{\text {dest }}$ values). Further work should obviously be dedicated to optimize the size of the local averaging cells used into CAN_EYE.

\subsection{LAI estimation from $P_{o}\left(57.5^{\circ}\right)$}

Effective LAI values derived from $P_{o}\left(57.5^{\circ}\right)$ (Fig. 10, RMSE $=0.68$, $y=0.7451 x, \quad r=0.97)$ show relatively similar performances compared to effective LAI values derived from $P_{\mathrm{o}}(\theta)$ (Fig. 4, RMSE $=0.63, y=0.781 x, r=0.95)$. The underestimation observed in LAI computed from directional gap fraction still remains.

Lang and Xiang LAI values $\left(\mathrm{L}_{\mathrm{LX}}\left(57.5^{\circ}\right)\right)$ derived from $\mathrm{P}_{\mathrm{o}}\left(57.5^{\circ}\right)$ lead to the best RMSE value of 0.46 but to an overestimation $\left(y=1.0881 x\right.$, Fig. 10) superior to that obtained with $L_{\mathrm{LX}}$ estimates $\left(y=1.038 x, \quad R M S E=0.56\right.$, Fig. 6). However, using $P_{o}\left(57.5^{\circ}\right)$ simplifies LAI estimation drastically because the retrieval of LAI is independent from the leaf angle distribution. The results are encouraging and this option could be further investigated.

\section{Conclusion}

Hemispherical photographs provide very pertinent information on canopy structure. Measurements are easy and fast to 
perform, and the processing of series of photographs is now possible and efficient with software such as CAN_EYE. However several aspects have to be considered with great care to get the best possible measurements of the gap fraction and the associated estimates of LAI. First, gap fraction measurements need to be representative of the canopy. For the crops studied here, the minimum distance required between sensor and canopy was $1 \mathrm{~m}$. Moreover, when feasible, there is a clear advantage in acquiring the photographs from above canopies and under overcast days to facilitate the classification. Indeed, exploitation of downward looking photographs taken under sunny days or upward looking photographs taken on low canopies $(<1 \mathrm{~m})$ may lead to uncertainties in gap fraction measurements not quantified in this paper. Replication of data is needed to evaluate systematically errors in LAI estimates associated with the acquisition conditions for the photographs (canopy to sensor distance, downward/upward looking, sky conditions, view restriction, etc.).

In this study, several methods of LAI estimation are compared and differences appear between crops. For wheat and sunflower, on almost all dates, the use of a clumping index leads to systematic LAI overestimation $(y=1.1039 x$ and $\mathrm{RMSE}=0.33$ for wheat; $y=1.3796 x$ and $\mathrm{RMSE}=0.83$ for sunflower). The $L_{\text {eff }}$ computed from the unidirectional gap fraction provides the best LAI estimates $(y=0.9540 x$ and RMSE $=0.15$ for wheat; $y=0.8427 x$ and $\operatorname{RMSE}=0.38$ for sunflower). For maize, the use of the clumping index leads to the best LAI estimates $(y=0.9010 x$ and RMSE $=0.39)$. Analysis of LAI retrieval on wheat at first stage of canopy development, reveals that at very low LAI values (LAI $<0.2$ ), the $L_{\mathrm{LX}}$ values were less than to $L_{\text {eff }}$ values suggesting that the limit of validity of the inversion procedure may have been reached.

However, even when the LAI estimates seem acceptable as for maize, compensation between leaf area index and leaf angle distribution may occur as already observed by Macfarlane et al. (2007). Moreover, our results reveal that $L_{\mathrm{LX}}$ estimates are correlated with the size of cells used to compute the clumping index, suggesting that the Lang and Xiang averaging method introduced into CAN-EYE must be optimized. Leblanc et al. (2005) and Macfarlane et al. (2007) showed that the clumping index - and then the LAI - was better retrieved for coniferous and eucalypt forests respectively when combining the gap size distribution and the Lang and Xiang averaging methods (Chen and Cihlar, 1995b; Leblanc et al., 2002). This approach could be implemented into CAN_EYE and tested on our data.

Finally, the method using gap fraction measured at $57.5^{\circ}$ provides also good fits between CAN_EYE and destructive LAI estimates. This is encouraging because the retrieval of effective LAI in that case is independent of the leaf angle distribution. This approach could be further investigated with photographs taken at this angle rather than just extracting the corresponding ring from hemispherical photographs. This will provide a far better spatial resolution leading to a much lower number of mixed pixels, although the smaller footprint has to be compensated by taking more images. In the latest CAN_EYE version, it is now possible to process panoramic images acquired with the camera oriented at $57.5^{\circ}$.

\section{Acknowledgements}

This work was made possible through the support of the French Ministry in charge of Research ("Reseau Terre et Espace"), the Ministry in charge of Environment (GICC programme), the CNES, and the Région Midi-Pyrénées Council. We also thank Mr. Gay and Mr. Kummel and the Ecole Supérieure d'Agriculture de Purpan for granting and facilitating our access to the fields of the Lamothe farm.

\section{R E F E R E N C E S}

Antunes, M.A.H., Walter-Shea, E.A., Mesearch, M.A., 2001. Test of an extended mathematical approach to calculate maize leaf area index and leaf angle distribution. Agric. For. Meteorol. 108, 45-53.

Baldocchi, D., Collineau, S., 1994. The physical nature of solar radiation in heterogeneous canopies: spatial and temporal attributes. In: Caldwell, M.M., Pearcy, M.W. (Eds.), Exploitation of Environmental Heterogeneity by Plants: Ecophysiological Processes Above- and Belowground. Academic Press, San Diego, CA, pp. 21-71.

Calvet, J.C., Noilhan, J., Roujean, J.-L., Bessemoulin, P., Cabelguenne, M., Olioso, A., Wigneron, J.-P., 1998. An interactive vegetation SVAT model tested against data from six contrasting sites. Agric. For. Meteorol. 92, 73-95.

Campbell, G.S., 1986. Extinction coefficients for radiation in plant canopies calculated using an ellipsoidal inclination angle distribution. Agric. For. Meteorol. 36, 317-321.

Campbell, G.S., 1990. Derivation of an angle density function for canopies with ellipsoidal leaf angle distributions. Agric. For. Meteorol. 49, 173-176.

Chen, J.M., 1996. Optically-based methods for measuring seasonal variation of leaf area index in boreal conifer stands. Agric. For. Meteorol. 80, 135-163.

Chen, J.M., Black, T.A., 1991. Measuring leaf area index of plant canopies with branch architecture. Agric. For. Meteorol. 57, 1-12.

Chen, J.M., Black, T.A., 1992. Defining leaf area index for non flat leaves. Plant Cell Environ. 15, 421-429.

Chen, J.M., Cihlar, J., 1995a. Plant canopy gap-size analysis theory for improving optical measurements of leaf-area index. Appl. Opt. 34 (27), 6211-6222.

Chen, J.M., Cihlar, J., 1995b. Quantifying the effect canopy architecture on optical measurements of leaf area index using two gap size analysis methods. IEEE Trans. Geosci. Remote Sens. 33, 777-787.

Combal, B., Baret, F., Weiss, M., 2002. Improving canopy variable estimation from remote sensing data by exploiting ancillary information. Case study on sugar beet canopies. Agronomie 22, 205-215.

España, M., Baret, F., Ariès, F., Andrieu, B., Chelle, M., 1999. Radiative transfer sensitivity to the accuracy of canopy structure description. The case of a maize canopy. Agronomie 19 (3-4), 241-254.

Frazer, G.W., Canham, C.D., Lertzman, K.P., 1999. Gap Light Analyzer (GLA), Version 2.0: Imaging software to extract canopy structure and gap light transmission indices from true-color fisheye photographs, users manual and program documentation, Copyright: 1999: Simon Fraser University, Burnaby, British Columbia and the Institute of Ecosystem Studies. Milbrook, New York.

Frazer, G.W., Fournier, R.A., Trofymow, J.A., Hall, R.J.A., 2001a. A comparison of digital and fisheye photography for analysis 
of forest canopy structure and gap light transmission. Agric. For. Meteorol. 109, 249-263.

Frazer, G.W., Trofymow, J.A., Lertzman, K.P., 2001b. Canopy openness and leaf area in chronosequences of coastal temperate rainforests. Can. J. For. Res. 30, 239-256.

Gower, S.T., Kucharik, C.J., Norman, J.M., 1999. Direct and indirect estimation of leaf area index, fapar, and net primary production of terrestrial ecosystems. Remote Sens. Environ. 70, 29-51.

Jonckheere, I., Fleck, Nackaerts, K., Muys, B., Coppin, P., 2005. Assessment of automatic gap fraction estimation of forests from digital hemispherical photography. Agric. For. Meteorol. 132, 96-114.

Jonckheere, I., Fleck, Nackaerts, K., Muys, B., Coppin, P., Weiss M., Baret, F., 2004. Review of methods for in situ leaf area index determination. Part I. Theories, sensors and hemispherical photography. Agric. For. Meteorol. 121, 19-35.

Kucharik, C.J., Norman, J.M., Murdock, L.M., Gower, S.T., 1997. Characterizing canopy non randomness with a multiband vegetation imager (MVI). J. Geophys. Res. 102 (D24), 2945529473.

Kussner, R., Mosandl, R., 2000. Comparison of direct and indirect leaf area index estimation of leaf area index in mature Norway Spruce stands of eastern Germany. Can. J. For. Res. 30, 440-447.

Lang, A.R.G., Xiang, Y., 1986. Estimation of leaf area index from transmition of direct sunlight in discontinuous canopies. Agric. For. Meteorol. 37, 229-243.

Leblanc, S.G., Chen, J.M., Kwong, M., 2002. Tracing Radiation and Architecture of Canopies. TRAC MANUAL, Version 2.1. Natural Resources Canada, 2.1: 1-25.

Leblanc, S.G., Chen, J.M., Fernandes, R., Deering, D.W., Conley, A., 2005. Methodology comparison for canopy structure parameters extraction from digital hemispherical photography in boreal forests. Agric. For. Meteorol. 129, 187-207.

Lemeur, R., Blad, B.L., 1974. A critical review of light models for estimating the shortwave radiation regime of plant canopies. Agric. For. Meteorol. 14, 255-286.

Levy, P.E., Jarvis, P.G., 1999. Direct and indirect measurements of LAI in millet and fallow vegetation in HAPEX-Sahel. Agric. For. Meteorol. 97, 199-212.

Macfarlane, C., Hoffman, M., Eamus, D., Kerp, N., Higginson, S. McMurtrie, R., Adams, M., 2007. Estimation of leaf area index in eucalpyt forest using digital photography. Agric. For. Meteorol. 143 (3-4), 176-188.

Miller, J.B., 1967. A formula for average foliage density. Aust. J. Bot. 15, 141-144.

Monsi, M., Saeki, T., 1953. Über den Lichtfaktor in den Pflanzengesellschaften und seine Bedeutung für die Stoffproduktion. Jpn. J. Bot. 14, 22-52.

Morisette, J., Baret, F., Privette, J.L., Myneni, R.B., Nickeson, J., Garrigues, S., Shabanov, N., Weiss, M., Fernandes, R., Leblanc, S.G., Kalacska, M., Sanchez-Azofeifa, G.A., Chubey, M., Rivard, B., Stenberg, P., Rautiainen, M., Voipio, P., Manninen, T., Pilant, D., Lewis, T., Iiames, J., Colombo, R.,
Meroni, M., Busetto, L., Cohen, W.B., Turner, D.P., Warner, D., Petersen, G.W., Seufert, G., Cook, R., 2006. Validation of global moderate resolution LAI Products: a framework proposed within the CEOS Land Product Validation subgroup. IEEE Trans. Geosci. Remote Sens. 44 (7), 1804-1817.

Muusche, S., Samson, R., Nachtergale, L., De Schrijver, A., Lemeur, R., Lust, N., 2001. A comparison of optical and direct methods for monitoring the seasonal dynamics of leaf area index in deciduous forest stands. Silva Fenn. 34 (4), 373-384.

Neumann, H.H., Den Hartog, G.D., Shaw, R.H., 1989. Leaf-area measurements based on hemispherical photographs and leaf-litter collection in a deciduous forest during autumn leaf-fall. Agric. For. Meteorol. 45, 325-345.

Nilson, T., 1971. Inversion of the frequency of gaps in plant stands. Agric. For. Meteorol. 8, 25-38.

Rich, P.M., 1990. Characterizing plant canopies with hemispherical photographs. Remote Sens. Rev. 5, 13-29.

Ross, J., 1981. The Radiation Regime and Architecture of Plant Stands. The Hague, $391 \mathrm{pp}$.

Sellers, J.P., Dickinson, R.E., Randall, D.A., Betts, A.K., Dall, F.G., Berry, J.A., Collatz, G.J., Denning, A.S., Mooney, H.A., Nobre, C.A., Sato, N., Field, C.B., Henderson-Sellers, A., 1997. Modeling the exchanges of energy, water, and carbon between continents and the atmosphere. Science 275, 502-509.

Spath, H., 1985. Cluster Dissection and Analysis: Theory, FORTRAN Programs, Examples. Halsted Press, zNew York.

Walter, J.M., 1989-2005. CIMES. A Package of Programs for the Assessment of Canopy Geometry through Hemispherical Photographs. Manual. Université Louis Pasteur, Institut de Botanique, Strasbourg. Institut de recherches pour le développement, Cayenne.

Wang, Y.P., Jarvis, P.G., 1988. Mean leaf angles for the ellipsoidal inclination angle distribution. Agric. For. Meteorol. 43, 319-321.

Wang, Y.P., Leuning, R., 1998. A two-leaf model for canopy conductance, photosynthesis and partitioning of available energy. I. Model description and comparison with a multilayered model. Agric. For. Meteorol. 91, 89-111.

Warren-Wilson, J., 1963. Estimation of foliage denseness and foliage angle by inclined point quadrats. Aust. J. Bot. 11, 95-105.

Weiss, M., Baret, F., Smith, G.J., Jonckheere, I., Coppin, P., 2004. Review of methods for in situ leaf area index (LAI) determination. Part II. Estimation of LAI, errors and sampling. Agric. For. Meteorol. 121, 37-53.

Welles, J.M., 1990. Some indirect method of estimating canopy structure. Remote Sens. Rev. 5, 31-43.

Welles, J.M., Norman, J.M., 1991. Instrument for indirect measurement of canopy architecture. Agron. J. 83 (5), 818-825.

Zhang, Y., Chen, J.M., Miller, J.R., 2005. Determining digital hemispherical photograph exposure for leaf area index estimation. Agric. For. Meteorol. 133, 166-181. 